\title{
Environmental changes and pre-Columbian human influence in the Amazon region - an introduction
}

\section{Heinz Veit, Bern}

Since the early days of colonization until today the Amazon lowlands have been full of mystery and magic stories. This is not only related to tales, sagas and novels but also to science. The green «Hyläa» of ALEXANDER VON HUMBOLDT is well-known for its outstanding biodiversity, and modern human impact is well documented. But what about the sensitivity of these tropical ecosystems to land-use and climatic changes at longer time scales? Very little is known about the evolution of landscapes and climate change in this area during the past millennia. The few results obtained in particular study areas are frequently interpreted as «typical» for the Amazon region. But one has to keep in mind that with an area of around 7 million $\mathrm{km}^{2}$, this is the most extensive catchment of the world. Neither the rainforests nor the savannah ecotones are uniform in terms of geology, topography, soils, fauna, flora, biodiversity, climate, inundations, geomorphodynamics, landscape evolution or anthropogenic influence.

With regard to past changes of the natural environments, most detailed information comes from pollen records, speleothems and geomorphologic evidence (e.g. dunes, river terraces, stone-lines). However, these are only needles in a haystack and alone do not contribute towards a profound understanding of the ecosystem dynamics. Human influence prior to colonization is almost unknown. The pre-Columbian Amazonian world view today ranges from pristine forest and savanna ecosystems with hunter-gatherers to «garden landscapes» dominated by the presence of humans and probably supporting complex structured communities. Moreover, the relationship of early humans in the Amazon with changing environments remains unclear. Was the population very sparse due to the harsh environmental conditions, or were the preColumbians able to adapt to and overcome the natural limitations? It is possible that the myth of the "wise Indians» reflects a level of knowledge and understanding in past generations which has since been forgotten. A good example for this are the interpretations of how «Terra Preta» soils, the Indian Black Earth, came to be: were they the deliberate improvement of the edaphic conditions of infertile tropical soils or just the occasional side effect of waste disposal?

In the current issue of Geographica Helvetica, some of the aspects and recent results of the SNF- funded project («Holocene hydrogeomorphology and pre-Colombian water management in the Llanos de Moxos, Bolivian Amazon») are presented. These are supplemented by contributions of three internationally well-known specialists. The first four papers deal with the Bolivian subcatchment of the Amazon, the two following papers give an overview over the greater Amazon region (Fig.1). The focus areas of each of the papers is marked in the map for better orientation.

Anna Plotzki, Jan-Hendrik May and Heinz Veit present data on the fluvial dynamics in the Llanos de Moxos. The Llanos, which occupy an extensive area of the Bolivian Amazon, are one of the largest seasonally inundated savannah regions of the world. Due to the strong seasonality and white water rivers with high sediment load, many of the big rivers like the Río Mamoré and Río Grande are subject to channel changes on annual to decadal time scales. Therefore, the Llanos are characterized by a dense net of inactive paleo-rivers. The reconstruction of these paleocourses is essential for the understanding of the ecosystem history as well as for the human earthworks present in the area.

These pre-Columbian earthworks are the focus of the paper by Umberto Lombardo, Elisa Canal-Beeby and Heinz Vert. The authors describe some of the main features and give a short review. They can show, that social complexity of these early cultures is related to the natural conditions. The types of these mannature relationships result in the definition of ecoarchaeological regions.

Roberto Langstroth Plotkin discusses the biogeography of the Llanos de Moxos and the question to which extent the modern picture is influenced by longterm human impact («domesticated landscape»?). He clearly points out that the general patterns of biological diversity are determined by the long-term environmental history and landscape conditions. At a regional scale it is only recently that human activities with cattle farming have a major impact upon flora and fauna.

The southernmost river contributing to the Amazon is the Río Parapetí, forming a huge megafan in the foreland of the Andes. A detailed analysis of the fluvial dynamics during the Holocene and the corresponding climatic and environmental interpretation is given in the paper of JAN-HENDRIK MAY. 


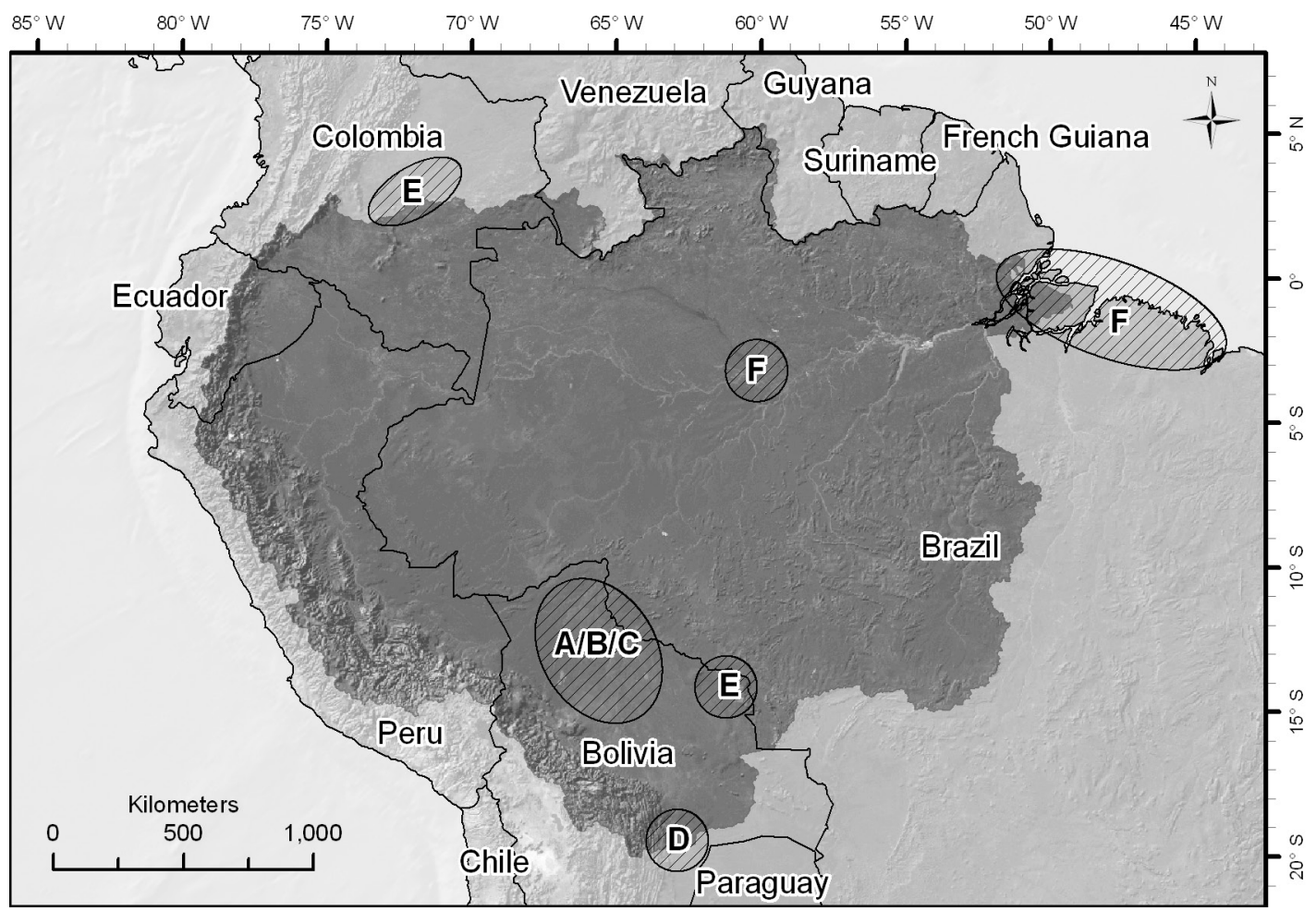

Fig. 1: Catchment of the Amazon River with research areas presented in this issue. A/B/C: papers by PLOTZKI et al., Lombardo et al. and LANGSTROTH; D: paper by MAY; E: paper by MAYLE; F: paper by BEHLING.

Amazonasgebiet mit Lage der Arbeitsgebiete, die im vorliegenden Heft behandelt werden. A/B/C: Beiträge von PlotzKi et al., Lombardo et al. und LANGStroth; D: Beitrag von MaY; E: Beitrag von MaYLE; F: Beitrag von Behling. Secteur de l'Amazone montrant les terrains de recherche présentés dans ce numéro. A/B/C: articles de PLOTZKI et al., Lombardo et al. et LANGStroth; D: article de MaY; E: article de MAYLE; F: article de Behling.

Source: U. Lombardo, based on the HydroSHEDS database (http://www.worldwildlife.org/science/projects/ freshwater/item1991.html)

The papers of Francis E. Mayle and Hermann BehLING present the palynological view of Holocene vegetation and climate evolution in the greater Amazon region. MAYLE's paper examines and compares fossil pollen records from the northern and southern limits of the Amazon. He finds a surprisingly similar pattern of rainforest dynamics on both sides of the equator during the Holocene and gives interpretations in terms of atmospheric paleocirculation. BeHLING in contrast, focuses on fossil pollen records in central, eastern and coastal Amazonia, adding a W-E perspective to the N-S perspective of MAYLE. Additionally, BeHLing shows the role of mixed influence of regional climate change and global sea-level changes, the latter influencing great expanses of lowland Amazonia.

\section{Acknowledgement}

The research in the Llanos de Moxos (papers by PlotzKi et al., Lombardo et al.) was funded by the Swiss National Science Foundation (SNF-project 200021-122289).

Prof. Dr. Heinz Veit, Institute of Geography, University of Bern, Hallerstrasse 12, CH-3012 Bern, Switzerland.

e-mail: veit@giub.unibe.ch 